\title{
Response to the Critical Comment by Bindler et al. on "Atmospheric Mercury Accumulation Rates between 5900 and 800 Calibrated Years BP in the High Arctic of Canada Recorded by Peat Hummocks"
}

\author{
William Shotyk $^{1 *}$, Nicolas Givelet ${ }^{1}$, Andriy K. Cheburkin ${ }^{1}$, Mickael E. Goodsite ${ }^{2}$, \\ and Fiona Roos-Barraclough ${ }^{3}$
}

1. Institute of Environmental Geochemistry, University of Heidelberg, INF 236, D-69120 Heidelberg, Germany

2. Environmental Chemistry Research Group, Department of Chemistry, University of Southern Denmark, Odense University, Campusvej 55, Odense M, Denmark

3. Zentralstrasse 68, 8212-Neuhausen am Rheinfall, Switzerland

* Corresponding author: Im Neuenheimer Feld 236, D-69120 Heidelberg, Germany.

E-mail: Shotyk@ugc.uni-heidelberg.de; Tel: +49 (6221) 54 4803; Fax: +49 (6221) 545228

Supporting Information (Environmental Science \& Technology)

Photo 1a. The hummock cored at Museum Station. The length of the white bar is 1 meter.

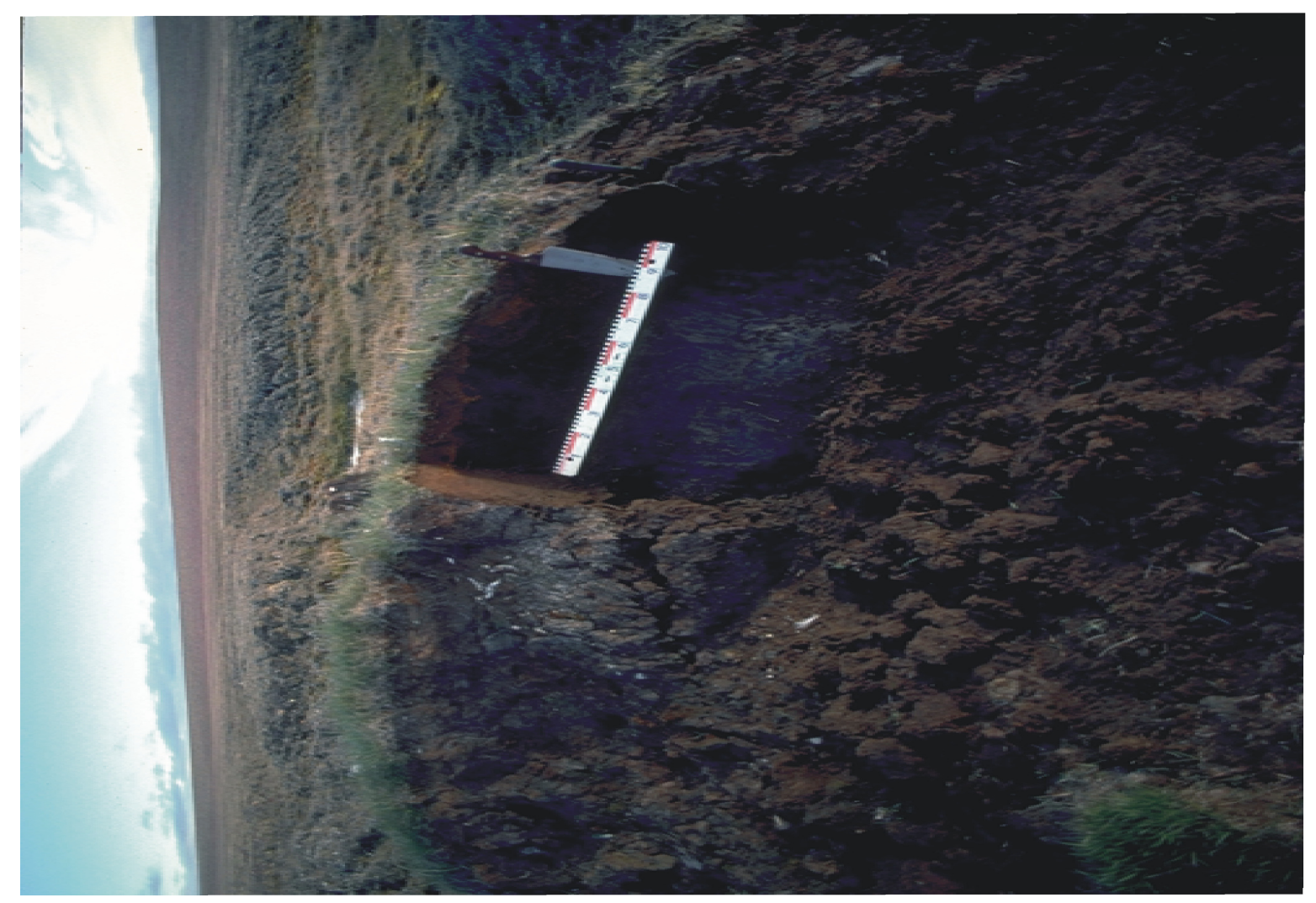


Photo 1b. Aerial view of the wetlands between Museum Station and Polar Bear pass.

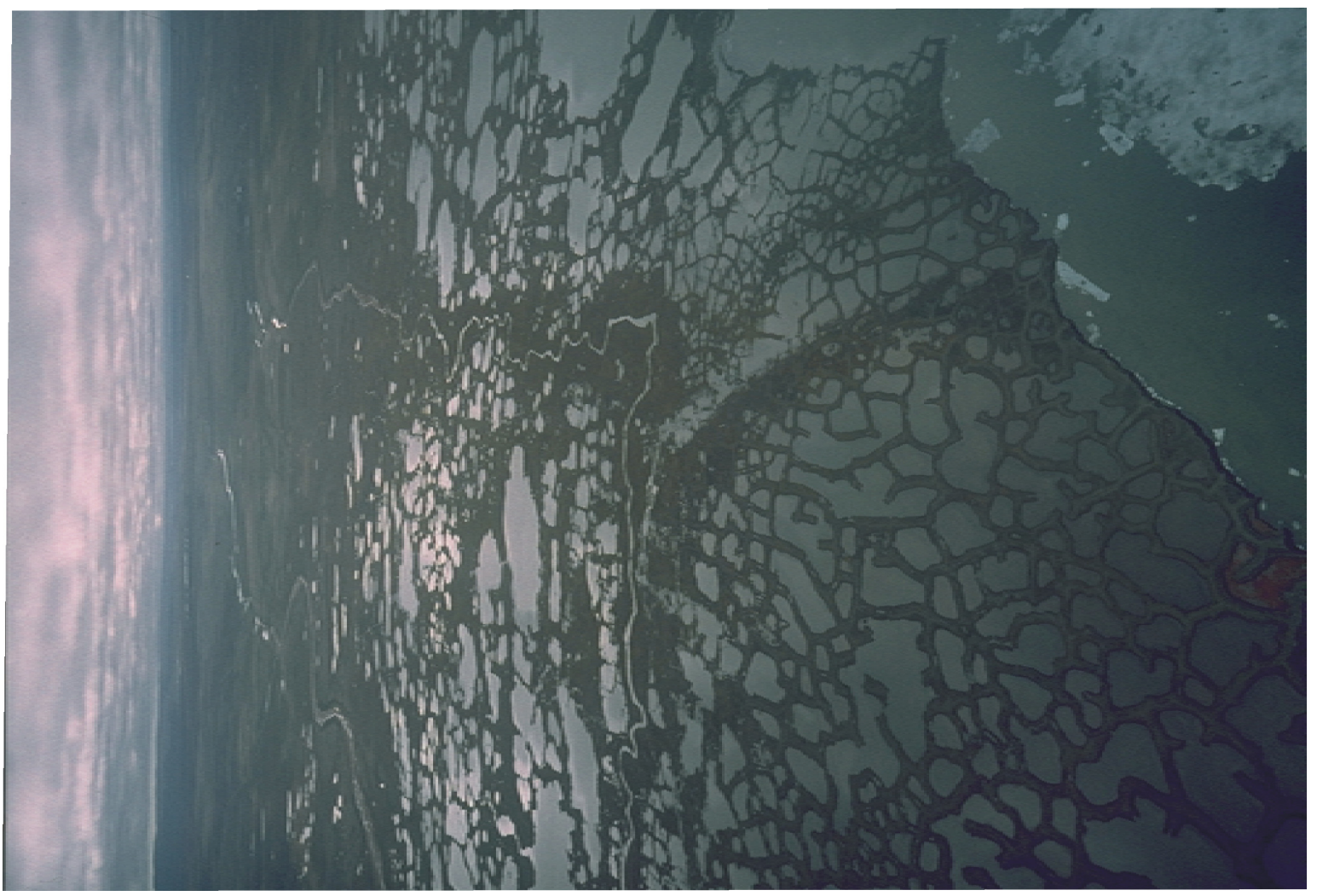

Photo 1c. Aerial view of the coring site at Bracebridge Inlet

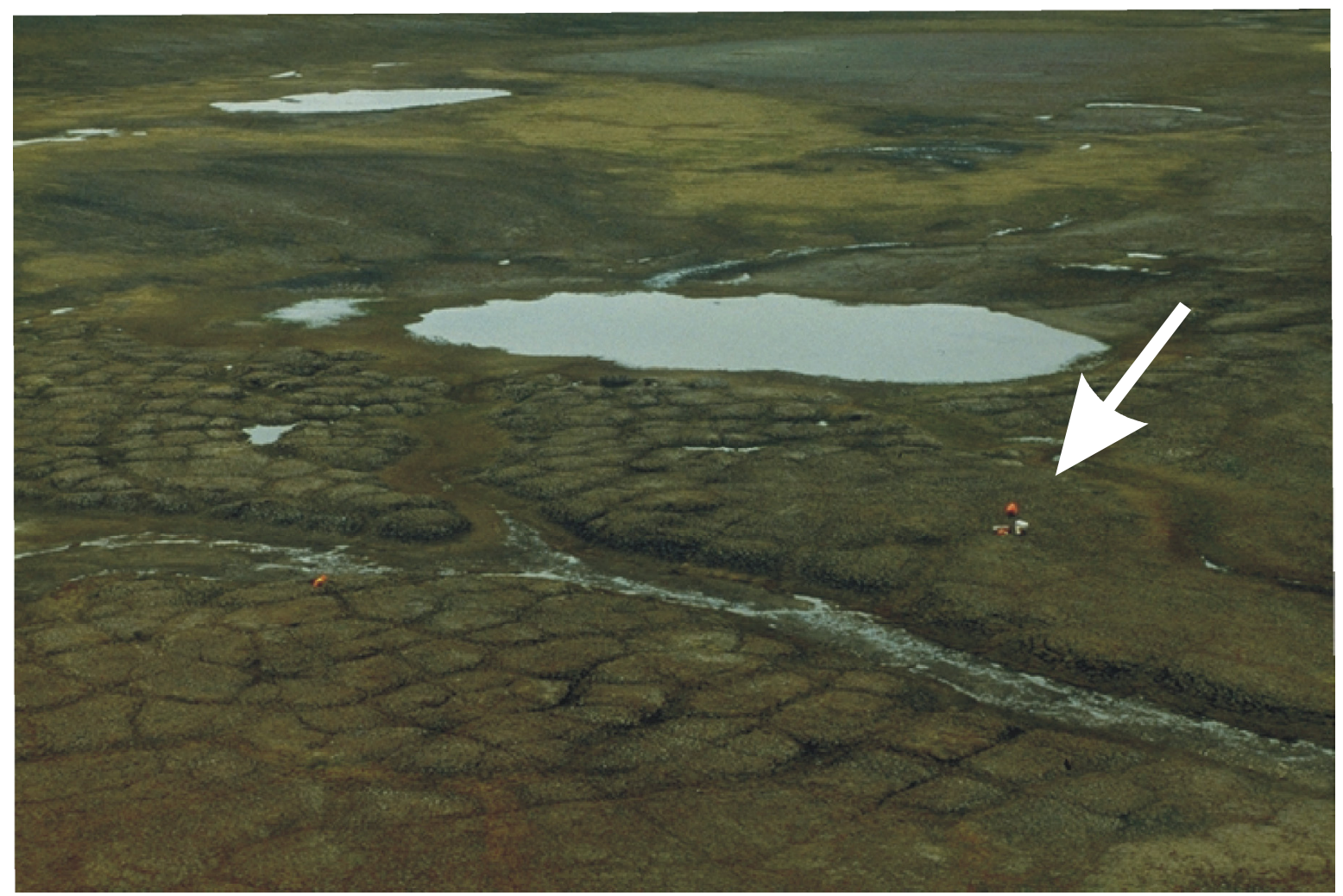

